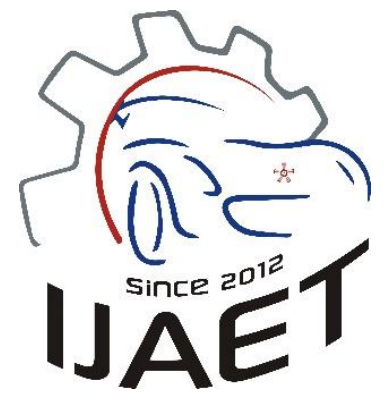

e-ISSN: 2146 - 9067

International Journal of Automotive

Engineering and Technologies

journal homepage: http:// http://dergipark.gov.tr/ijaet

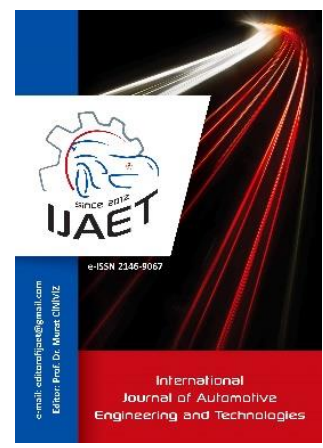

Original Research Article

\title{
The experimentally and numerically determination of the drag coefficient of a bus model
}

hosted by Journal Park

Cihan Bayındırlı ${ }^{*}$, Mehmet Çelik ${ }^{1}$

${ }^{1}$ Nigde Vocational School of Technical Sciences, Niğde Omer Halisdemir University, 51200 Niğde, Turkey

\author{
ARTICLE INFO \\ * Corresponding author \\ cbayindirli@ohu.edu.tr \\ Received: May 11, 2018 \\ Accepted: October 18, 2018 \\ Published by Editorial Board \\ Members of IJAET \\ (C) This article is distributed by \\ Turk Journal Park System \\ under the CC 4.0 terms and \\ conditions.
}

\begin{abstract}
In this study, the drag coefficient of a 1/33 scaled bus model was determined by experimentally in wind tunnel and numerically in Fluent ${ }^{\circledR}$. The tests were performed at 6 different free flow velocities and between the range of 382866 792900 Reynolds numbers and $13.54 \mathrm{~m} / \mathrm{s}-28.05 \mathrm{~m} / \mathrm{s}$ speeds. The three similarity conditions were provided in tests. The flow analyses were conducted in $1 / 40$ scaled wind tunnel as experimentally using Reynolds independent. The aerodynamic drag coefficient $\left(\mathrm{C}_{\mathrm{D}}\right)$ of the bus model was calculated as 0.633 in wind tunnel. The experimental results of bus model are verificated by numerical flow analysis in Fluent ${ }^{\circledR}$ program. According to numerical results, the drag coefficient of bus model is calculated as 0.645 with $1.81 \%$ error margin.

Keywords: Vehicle aerodynamic, drag coefficient, wind tunnel, bus model, CFD, Fluent
\end{abstract}

\section{Introduction}

The aerodynamic drag force significantly affects the vehicle's performance, fuel consumption, acceleration properties, handling characteristics, environmental pollution, noise and comfort. Moreover, aerodynamic drag coefficient is increased proportionally with the square of the speed. This status makes more important aerodynamic structure of buses which perform a large part of the transportation out of the city at high speeds. The fuel consumption reduces about $1 \%$ when the $C_{D}$ coefficient of a vehicle reduces by $2 \%$ at high speeds [1]. Cui et al. (2015) investigated the effect of synthetic air jetting on an Ahmed body model using the Large Eddy Smilation turbulence model in the CFD method. The results of numerical studies were verified with experimental studies. They reduced aerodynamic drag coefficient by $3 \%$ -
$9 \%$ by regularly air jetting behind the model [2]. According to Mohamed-Kassim and Filippone (2010), the fuel consumption can be improved from $1 \%$ to $17 \%$ using passive flow control parts on truck trailers. By improving the spoiler design $9-17 \%$, aerodynamic improvement can be achieved, 4-6\% with trailer skirts, and 0-4\% with closing the air gaps [3]. Ji-qiang et al. (2017) experimentally investigated the aerodynamic structure of a high-speed train in different turbulence intensities. They determined the pressure coefficient values on the train. They found aerodynamic drag coefficients under different turbulence intensities in the range of 0.3-8.6. As the turbulence intensity increases, the $C_{D}$ coefficient and pressure coefficient values decrease [4. Hassan et al. (2014) improved to drag force of sedan racing car by changing the rear bumper structure. By using the CFD 
method and the k-epsilon turbulence model, they found the $C_{D}$ coefficient of the model vehicle as 0.323 as a result of numerical analysis. They have reduced $\mathrm{C}_{\mathrm{D}}$ coefficient by up to $22.13 \%$ with 5 buffer diffuser which they developed. They determined the minimum $C_{D}$ coefficient as 0.25 . They stated that this was caused by reduced the negative pressure area behind the car [5]. Chilbule et al. (2014) examined the aerodynamic structure of a truck trailer model by the CFD method. They improved the $\mathrm{C}_{\mathrm{D}}$ coefficient of the truck trailer model by $21 \%$ by adding passive flow control components consisting of spoiler, six vortex holders and a trailer back extension. They stated that this result would reduce the fuel consumption about 4 liters at $100 \mathrm{~km}$ [6]. Patil et al. (2012) examined the flow structure around a bus model using the CFD method. They developed three models to reduce the drag force of the bus model. In their study, they determined the $\mathrm{C}_{\mathrm{D}}$ coefficient of the base model bus as 0.53 . They reduced the $\mathrm{C}_{\mathrm{D}}$ coefficient to 0.49 by modifying the front and rear surface of the bus. They have achieved to reduce $C_{D}$ coefficient to 0.39 by adding the side panel, 0.40 by rear spoiler. Thus, they achieved an aerodynamic improvement as respectively $6.57 \%, 25.82 \%$ and $24.42 \%$ [7]. Chowdhury, et al. (2013) have developed aerodynamic parts to reduce the drag coefficient for heavy vehicles. They achieved average $26.1 \%$ aerodynamic improvement by changing spoiler structure, closing the distance between truck-trailer, and adding some parts to reduce drag which was caused by the wheels. The spoiler design could improve drag force by $17.6 \%$ [8]. Akansu et al. (2011) experimentally examined the effect of the angle of attack on the swirl break in the case of a flow around a square cross-section rod and a circular cross-section rod used as a passive flow control element. Features of flow separation, reattachment and vortex formation region are presented. At the a $=0^{\circ}$ attack angle at $\mathrm{L} / \mathrm{D}=2$ and 3 positions, significant decreases in drag force were obtained [9]. Bayındırlı et al. (2018) determined the drag coefficient of 1/64 scaled bus model as 0.658 by numerically in Fluent ${ }^{\circledR}$. The drag coefficient of bus model is decreased by passive flow control method [10].

The aim of this study is to determine of drag coefficient of a bus model experimentally and numerically. To examine the flow structure around the bus model, detect zones on bus model which form high aerodynamic drag. This paper also includes flow visualizations and pressure based distribution on the bus model.

\subsection{Experimental setup}

The suction type wind tunnel used in experimental studies. The test region is $40 \times 40 \times 100 \mathrm{~cm}$. The frequency inverter is used to control rpm of the fan motor. The frequency inverter operates in the range of $0-50 \mathrm{~Hz}$ and has $0.1 \mathrm{~Hz}$ step, to control $4 \mathrm{~kW}$ powered axial fan of $700 \mathrm{~mm}$ diameter. In experimental studies, Honeywell Model 41 load cell was used to measure the drag force with $0.1 \%$ accuracy which measures $5 \mathrm{lb}$ to $500,000 \mathrm{lb}$ force, with 4 $\mathrm{mA}-20 \mathrm{~mA}$ and $0 \mathrm{Vdc}$ to $5 \mathrm{Vdc}$ output voltage. During the force measurement, a total of 20000 data were acquired for 20 seconds at $1000 \mathrm{~Hz}$ frequency at each free flow rate and the average of this 20000 value was taken as drag force. Turbulence intensity calculated by Dantec CTA multichannel hot wire anemometer. It was determined that turbulence intensity below $1 \%$ in the wind tunnel.

The wind tunnel tests were carried out in the range of $3.8 \times 10^{5}-7.9 \times 10^{5}$ Reynolds numbers. The minimum and maximum free velocities are in the range of $0-30 \mathrm{~m} / \mathrm{s}$. The blocking rate is $6.81 \%$. The view of the test devices and wind tunnel is given in Fig. 1a and Fig. 1b.

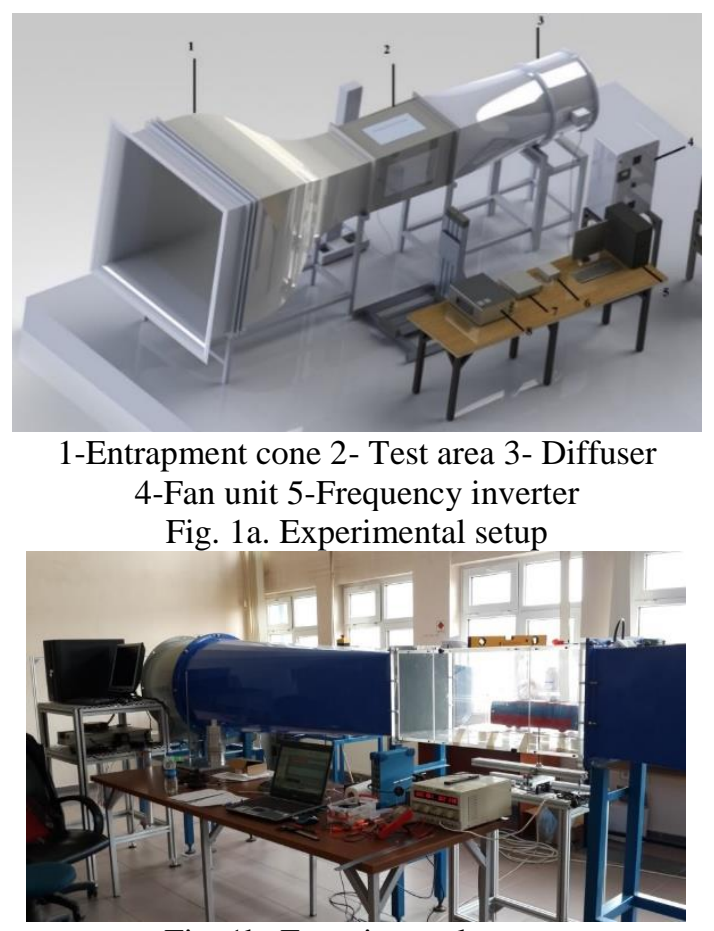

Fig. 1b. Experimental setup 
The free flow velocities of the wind tunnel were calculated with a pitot tube. The 24-bit OROS OR35 multichannel data acquisition card and Navigate data acquisition software were used to collect values from the load cell, $\pm 0.02^{\circ}$ phase, \pm 0.02 amplitude and dynamic $>120 \mathrm{~dB}$ sensitivity. The experiments were performed on the test model which is shown in Figure 2 and 3. In this study, the bus model which is examined aerodynamically and numerically is $1 / 33$ scale licensed model. The measurement of the bus model was precisely carried out with threedimensional scanning device and was created by computer-aided drawing method. The width of model bus $10.01 \mathrm{~cm}, 9.63 \mathrm{~cm}$ and height 44.1 $\mathrm{cm}$.

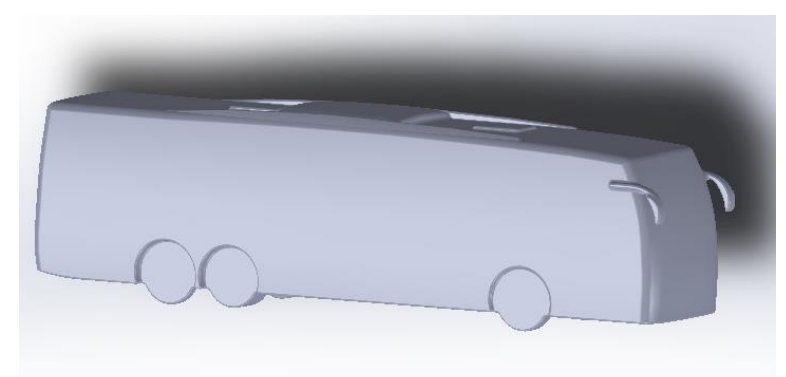

Fig. 2. Drawing data of bus model

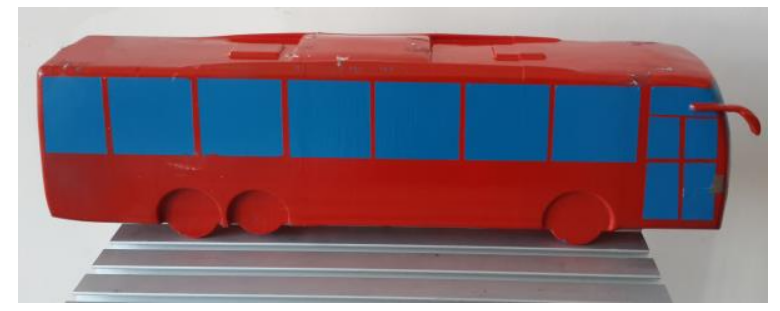

Fig. 3. The produced bus model in 3D printer

\subsection{CFD Setup}

The Fluent ${ }^{\circledR}$ program used in flow analysis. It can solve general integral equations for continuity, momentum, energy, turbulence on the finite volume method. When these equations come into equilibrium at every point in the solution area, convergence occurs in the solution. For each fluid variant, residuals indicate the severity of the error in the solution. In this study, convergence criteria is taken as 1.0 $\times 10^{3}$ for continuity, $\mathrm{x}$-velocity, $\mathrm{y}$-velocity and $\mathrm{z}$ velocity. The intensity of turbulence is taken as $1 \%$. The air density is taken as $1 \mathrm{~kg} / \mathrm{m}^{3}$ and the dynamic viscosity is $1.56 \times 10^{-5}$. The front surface area of the vehicle is calculated as $0.01089 \mathrm{~m}^{2}$ from the reports-projected area. The analysis was made as standard initialization using standard wall functions and Simple Least
Squared Cell d k- $\varepsilon$ RNG turbulence model. The numeric flow analysis was carried out in the Fluent ${ }^{\circledR}$ program using Workstation computer which has Intel ${ }^{\circledR}$ Xeon ${ }^{\circledR}$ CPU E3-1270 V5 3.60 $\mathrm{GHz}$ processor and $32 \mathrm{~Gb}$ Ram.

\subsubsection{RNG k- $\varepsilon$ Turbulence Model Selection}

The basic aim of turbulence models is to improve the calculation methods. The RNG k- $\varepsilon$ model provides a different analytical equation for drag effects, which is used to calculate the effects of low Reynolds numbers. Using of this feature makes the near-wall approach reliable. The $\mathrm{k}-\varepsilon$ model is used the most model in practice and is the model that yields reliable results when compared with experimental data. RNG k- $\varepsilon$ model is used as the turbulence model in this study because it is accepted in the literature, it is compatible with the experimental results and the analysis time is shorter.

\subsubsection{General Equations}

The Fluent program solves the general integral equations for continuity, momentum, energy, turbulence using the finite volume method. Continuity and momentum equations are used in solving the finite volumes with computational flow dynamics (CFD). In practice, it is difficult to solve these equations analytically. Therefore, these equations are solved numerically using packet programs.

Continuity equation

The continuity equation is expressed as the mass balance in the control volume in incompressible a flow [12].

$\frac{\partial u}{\partial x}+\frac{\partial v}{\partial y}+\frac{\partial w}{\partial z}=0$

\section{Momentum equation}

According to Newton's second law, the rate of change of the momentum of a fluid fraction is equal to the total of the forces acting on that fluid fraction. The momentum increase rate in the $\mathrm{x}, \mathrm{y}$ and $\mathrm{z}$ directions of the unit volume of a fluid fraction is respectively expressed in terms of $\rho \frac{D u}{D t}, \rho \frac{D v}{D t} \rho \frac{D w}{D t}[12]$.

The $\mathrm{x}$-component of the momentum equation [12].

$$
\rho \frac{D u}{D t}=\frac{\partial\left(-p+\tau_{x x}\right)}{\partial x}+\frac{\partial \tau_{y x}}{\partial y}+\frac{\partial \tau_{z x}}{\partial z}+S_{M_{x}}
$$


The y-component of the momentum equation [12].

$$
\rho \frac{D v}{D t}=\frac{\partial \tau_{x y}}{\partial x}+\frac{\partial\left(-p+\tau_{y y}\right)}{\partial y}+\frac{\partial \tau_{z y}}{\partial z}+S_{M y}
$$

The z-component of the momentum equation [12].

$$
\rho \frac{D w}{D t}=\frac{\partial \tau_{x z}}{\partial x}+\frac{\partial \tau_{y z}}{\partial y}+\frac{\partial\left(-p+\tau_{z z}\right)}{\partial z}+S_{M_{z}}
$$

\section{Navier-Stokes equations}

Navier - Stokes and continuity equations are also referred to as differential motion equations. When these equations are solved, some assumptions are taken and pressure and three components of velocity $(\mathrm{x}, \mathrm{y}, \mathrm{z})$ are calculated. The most useful way to develop the finite volume method of Navier - Stokes equations [12].

$$
\begin{aligned}
& \rho \frac{D u}{D t}=-\frac{\partial p}{\partial x}+\operatorname{div}(\mu \operatorname{grad} u)+S_{M_{x}} \\
& \rho \frac{D v}{D t}=-\frac{\partial p}{\partial y}+\operatorname{div}(\mu \operatorname{grad} v)+S_{M y} \\
& \rho \frac{D w}{D t}=-\frac{\partial p}{\partial z}+\operatorname{div}(\mu \operatorname{grad} w)+S_{M z}
\end{aligned}
$$

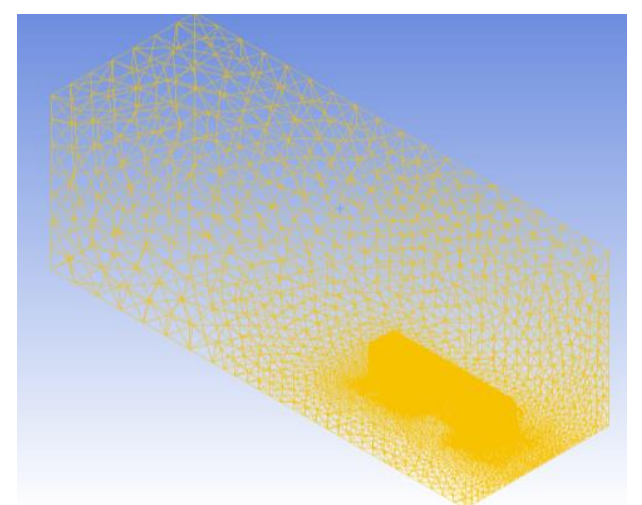

Fig.6a. The mesh distribution on model bus

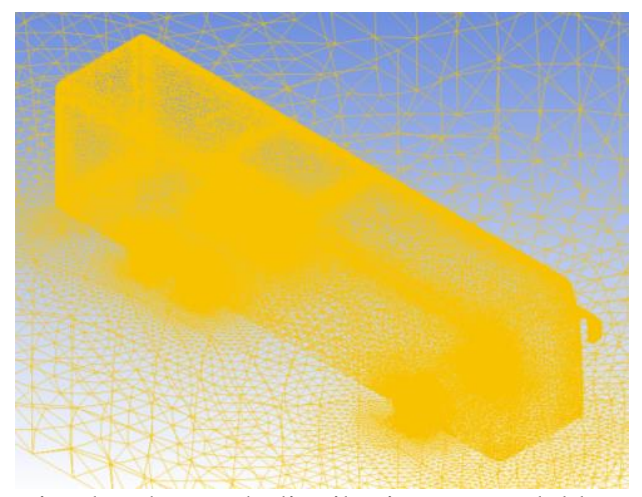

Fig.6b. The mesh distribution on model bus

As seen in Fig. 6 a,b the mesh structure is formed more frequently in the regions which affects the aerodynamic structure of the model bus significantly, the boundary definitions are made and the mesh file is transferred to the setup section. For the bus model, 2723079 triangular volumes cell structure (tedrahedrons) was created. The boundary conditions in the solution area are defined as inlet, outlet, wall and bus model.

The $\mathrm{C}_{\mathrm{D}}$ graph and convergence history is seen in Fig. 7. As a results of the flow analysis, the drag force which acted on the model bus was obtained after 1000 iteration results and the $C_{D}$ coefficient was determined.

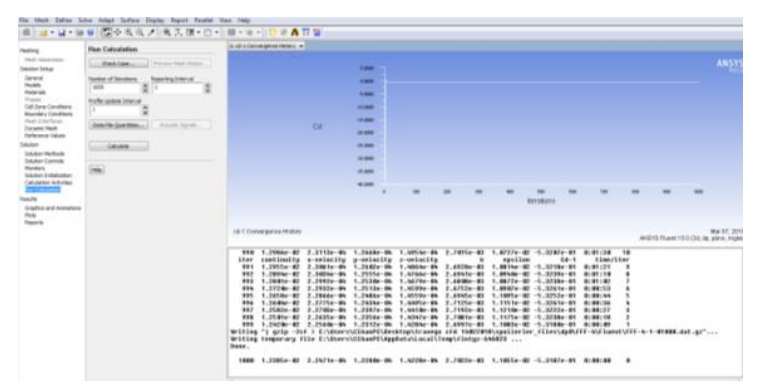

Fig.7. The $\mathrm{C}_{\mathrm{D}}$ graph and convergence

The drag coefficient $\left(C_{D}\right)$ is the function of the drag force $F_{D}$, density $\rho$, free flow velocity $V$ and front view area and it is given in Eq. (8).

$\mathrm{C}_{\mathrm{D}}=\frac{F_{D}}{1 / 2 \rho \mathrm{V}^{2} \mathrm{~A}}$

\subsection{Mesh Independent in CFD Analysis}

It is very important to establish a smooth and high quality mesh in the numerical analysis on complicated model. As the complexity of the analyzed geometries increases, it becomes more difficult to obtain mesh quality. The geometry of bus has got a lot of curved parts and the mesh quality could not be obtained at the desired level which is given in Fig.8.

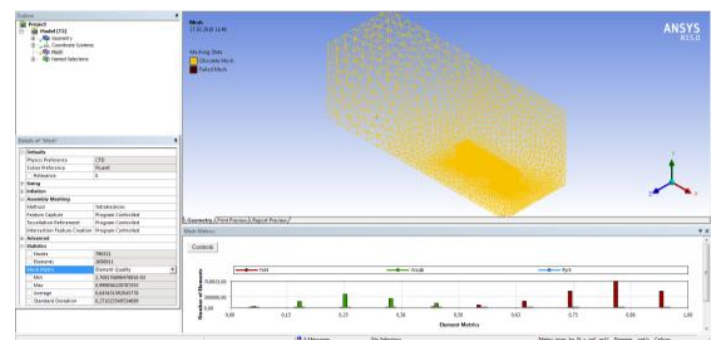

Fig.8. Mesh quality on bus model

In this study, the average element quality was 0.68 for bus model. It is not recommended that this value is higher than 0.5 . One of the methods to verify numerical studies is the independence test from the mesh. If the result does not change after a certain value despite the increase in the number of mesh in the numerical solution, 
independence in the solution from the mesh is obtained. In this study, as shown in Table 1. mesh independence tests were carried out for 12 different triangular volumes (tetrahedrons) mesh structure at $28.05 \mathrm{~m} / \mathrm{s}\left(7.9 \times 10^{5}\right.$ Reynolds number) free flow rate for bus model.

Table 1. Mesh independence test results at $7.9 \times 10^{5}$

\begin{tabular}{lrl}
\multicolumn{3}{c}{ Reynolds number } \\
\hline $\begin{array}{c}\text { Reynolds } \\
\text { Number }\end{array}$ & $\begin{array}{c}\text { Mesh } \\
\text { Number }\end{array}$ & $\mathbf{C}_{\mathbf{D}}$ \\
\hline $\mathbf{7 9 2} 900$ & 650306 & 0,56 \\
$\mathbf{7 9 2} 900$ & 954520 & 0,72 \\
$\mathbf{7 9 2 9 0 0}$ & 1060230 & 0,68 \\
$\mathbf{7 9 2} 900$ & 1550251 & 0,66 \\
$\mathbf{7 9 2 9 0 0}$ & 1995742 & 0,64 \\
$\mathbf{7 9 2} 900$ & 2227102 & 0,66 \\
$\mathbf{7 9 2 9 0 0}$ & 2602154 & 0,65 \\
$\mathbf{7 9 2} 900$ & $\mathbf{2 7 2 3 0 7 9}$ & $\mathbf{0 , 6 5}$ \\
$\mathbf{7 9 2} 900$ & 3565468 & 0,66 \\
$\mathbf{7 9 2} 900$ & 4011160 & 0,64 \\
\hline
\end{tabular}

The independence tests from the mesh were conducted on 12 different mesh numbers for bus model. As seen in Fig. 9, the $C_{D}$ coefficient was obtained at approximate values after 1550251 mesh numbers. In this study, 2723079 number of mesh was formed for bus model.

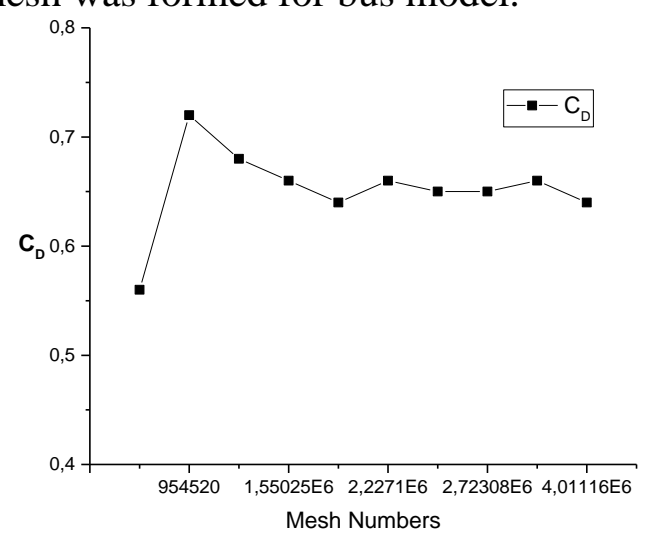

Fig. 9. The graph of mesh independent

These mesh number is in the region where the mesh independence is obtained. Therefore, it has been accepted that flow analyzes are performed independently from the mesh quality. The faults which were caused mesh number and quality in numerical results were ignored.

\section{Experimental Results}

\subsection{The drag coefficient of model bus}

As seen in Table 2 and Fig. 10, as a result of 3 repeated experimental tests the $C_{D}$ coefficient of the model bus was determined as 0.633 average. This result coherent with the literature.

Table 2. Aerodynamic drag coefficients of model bus

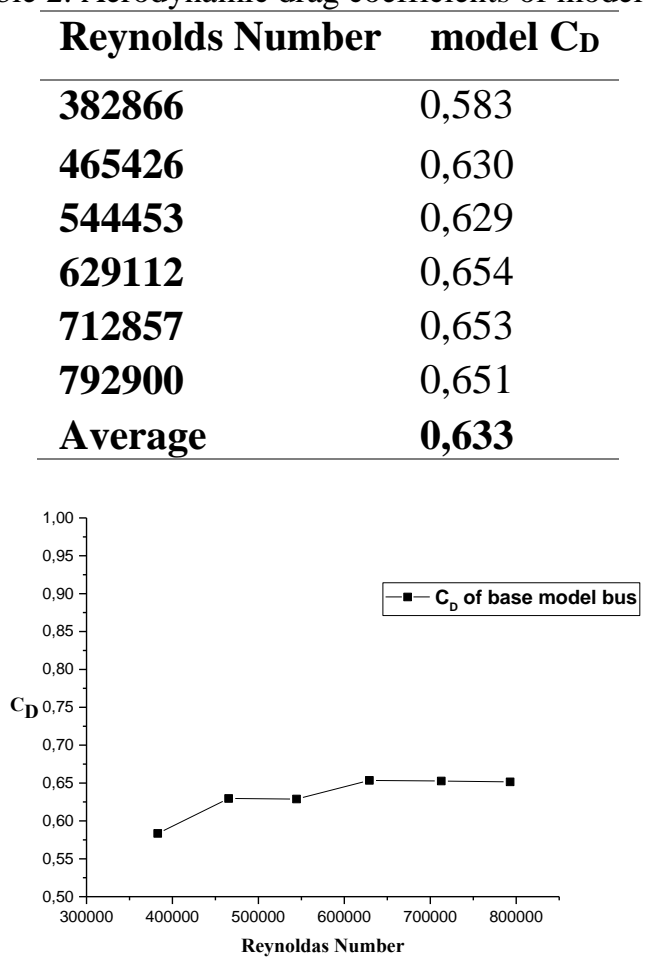

Fig. 10. The graph of drag coefficient of model bus

\subsection{Uncertainty Analysis of Experimental Results}

In this study, the results of the uncertainty analysis of the calculated parameters are given below.

\subsubsection{Calculation of the uncertainty value of the Reynolds number}

Uncertainty value for the $\mathrm{Re}$ number was obtained as $3,87 \%$.by writing $\rho$, U $\mathrm{U}_{\text {Pitot }}, \mathrm{H}$ and $\mu$ argument of uncertainty values instead of Eq. 9.

$\mathrm{u}_{\mathrm{Re}}=\frac{\mathrm{w}_{\mathrm{Re}}}{\mathrm{Re}}=\left[\left(\mathrm{u}_{\rho}\right)^{2}+\left(\mathrm{u}_{\text {Pitot }}\right)^{2}+\left(\mathrm{u}_{\mathrm{H}}\right)^{2}+\right.$

$\left.\left(u_{\mu}\right)^{2}\right]^{1 / 2}$

\subsubsection{Calculation of the uncertainty value of the drag force}

The uncertainty values that are acting coefficient of drag forces was obtained as $4.5 \%$. It was calculated for $\mathrm{U}=10 \mathrm{~m} / \mathrm{s}$ and $\mathrm{Re}=312$ 000 value. 
$\frac{\mathrm{w}_{\mathrm{F}_{\mathrm{D}}}}{\mathrm{F}_{\mathrm{D}}}=\left[\left(\frac{\mathrm{w}_{\mathrm{X}_{1}}}{\mathrm{X}_{1}}\right)^{2}+\left(\frac{\mathrm{w}_{\mathrm{X}_{2}}}{\mathrm{X}_{2}}\right)^{2}+\right.$

$\left.\left(\frac{w_{X_{3}}}{\mathrm{X}_{3}}\right)^{2}+\left(\frac{w_{X_{4}}}{\mathrm{X}_{4}}\right)\left(\frac{w_{X_{4}}}{\mathrm{X}_{4}}\right)+\left(\frac{w_{X_{5}}}{\mathrm{X}_{5}}\right)^{2}\right]^{1 / 2}$

\subsubsection{Calculation of the uncertainty value of the aerodynamic drag coefficient}

The uncertainty value of the aerodynamic force coefficient was obtained as $4.7 \%$.by writing $\mathrm{F}$, $\rho, A$, the argument of uncertainty values instead of Eq. 11.

$\mathrm{u}_{\mathrm{C}_{\mathrm{D}}}=\frac{\mathrm{w}_{\mathrm{C}_{\mathrm{D}}}}{\mathrm{C}_{\mathrm{D}}}=\left[\left(\mathrm{u}_{\mathrm{F}_{\mathrm{D}}}\right)^{2}+\left(\mathrm{u}_{\rho}\right)^{2}+4\left(\mathrm{u}_{\mathrm{pitot}}\right)^{2}+\right.$ $\left.\left(\mathrm{u}_{\mathrm{A}}\right)^{2}\right]^{1 / 2}$

\section{The Verification of Experimental Results by CFD}

The results of the experimental studies must verificate on vehicle aerodynamics studies. Some authors compare results with literature data some of them confirm with CFD. In this study the experimental results verificated by CFD on same 6 Reynolds number and 6 free flow velocity.

\subsection{The verification of experimental result of model}

The $C_{D}$ coefficient of the model bus was determined as 0.645 numerically after the 1000 iterations at 6 free flow velocity by using CFD method. It was obtained as 0.633 by experimentally in wind tunnel tests. There is a $1.81 \%$ difference between the experimental result and the CFD result. This difference is acceptable. It can be results from the uncertainty of the wind tunnel, calibration error rate or vibration in high speeds of wind tunnel. It was determined that $89,07 \%$ of the total drag force was caused by pressure induced and $10,93 \%$ by friction induced. According to same Reynolds number, the comparing $\mathrm{C}_{\mathrm{D}}$ values are given in Table 3, and, $C_{D}$ graph is in Fig. 11, and the flow images are in Figures 12, 13 and 14.

Table 3. Comparing of experimental-numerical drag coefficients for bus model

\begin{tabular}{lcc}
\hline $\begin{array}{l}\text { Reynolds } \\
\text { Number }\end{array}$ & $\begin{array}{c}\text { Numerical } \\
\mathbf{C}_{\mathbf{D}}\end{array}$ & $\begin{array}{c}\text { Experimental } \\
\mathbf{C}_{\mathbf{D}}\end{array}$ \\
\hline $\mathbf{3 8 2 8 6 6}$ & 0,65864 & 0,583 \\
$\mathbf{4 6 5 4 2 6}$ & 0,66105 & 0,630 \\
$\mathbf{5 4 4 4 5 3}$ & 0,66806 & 0,629 \\
$\mathbf{6 2 9 1 1 2}$ & 0,64731 & 0,654
\end{tabular}

\begin{tabular}{lcc}
$\mathbf{7 1 2 8 5 7}$ & 0,60808 & 0,653 \\
$\mathbf{7 9 2 9 0 0}$ & 0,62529 & 0,651 \\
Average & $\mathbf{0 , 6 4 5}$ & $\mathbf{0 , 6 3 3}$ \\
\hline
\end{tabular}

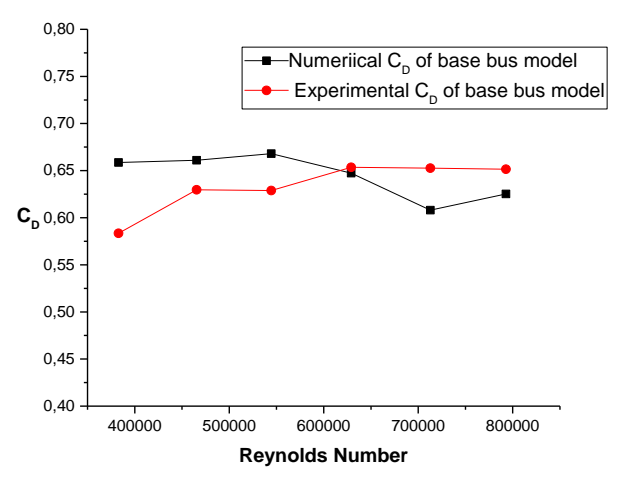

Fig. 11. Comparing drag coefficient graph $\left(\mathrm{C}_{\mathrm{D}}\right)$ of model bus

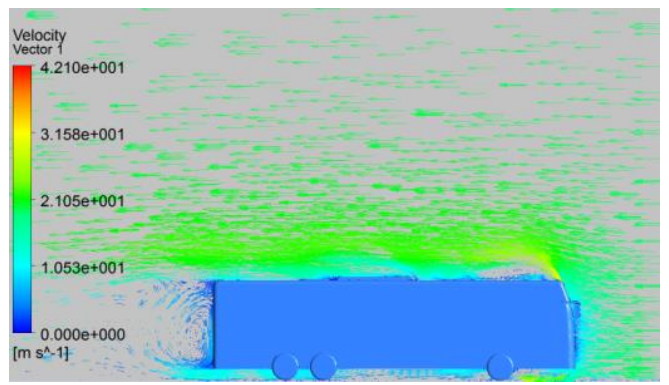

Fig. 12. The vector image of the effecting wind speed to model bus at $5.4 \times 10^{5}$ Reynolds number

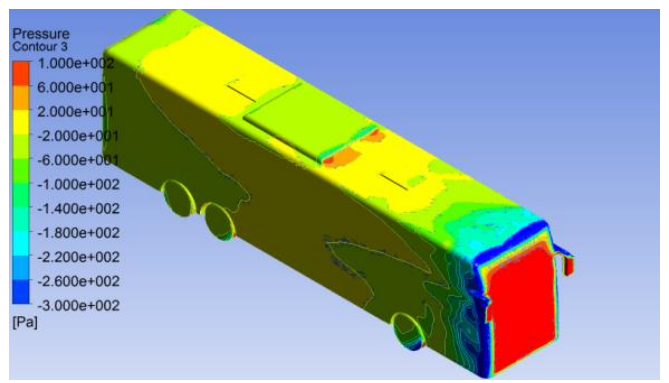

Fig. 13. The pressure distribution on the model bus at $5.4 \times 10^{5}$ Reynolds number

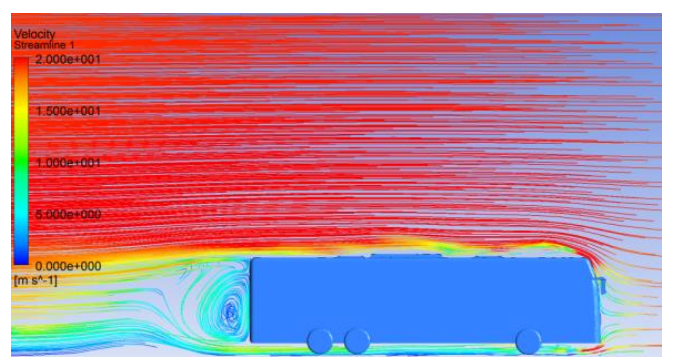

Fig.14. The streamline image of the wind speed around the bus model at $5.4 \times 10^{5}$ Reynolds number 


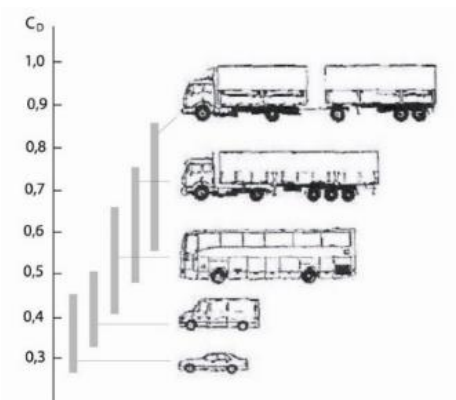

Fig. 15. Aerodynamic drag coefficients of various vehicles [1 and 10]

The determined $C_{D}$ value both experimentally and numerically for the model bus are coherent with the literature as seen in Fig. 15.

\section{Conclusions}

In this study, the flow structure around a bus model is examined experimentally and numerically. The summaries of results in the studies are presented below. The aerodynamic drag coefficient of the model bus is calculated both in wind tunnel and CFD, which are coherent with the literature values. To verificate of wind tunnel result flow analysis was made at the same tests conditions. The experimental result is verificated \%1.81 error margin. In this study, $89.07 \%$ of total drag force of model bus is pressure induced and $10.93 \%$ is friction induced. It has been seen that there is a potential for reducing friction induced drag on the bus model. It is seen in flow visualizations where pressure based drag force is very high on front bumper and windshield.

\section{Acknowledge}

This study was supported by Niğde Ömer Halisdemir University Scientific Research Projects Coordination Unit with ref. FEB 2016/24 BAGEP. The authors would like to thank to Niğde Ömer Halisdemir University Scientific Research Projects Coordination Unit and supervisor of project Prof. Dr. Yahya Erkan AKANSU for their support.

\section{References}

1. Wood, R.M. and Bauer, S.X.S. (2003), Simple and low cost aerodynamic drag reduction devices for tractor-trailer trucks. SAE Technical Paper, 01-3377, 1-18.

2. Cui, W. Zhu, H. Xia, C. Yanga, Z. (2015). Comparison of steady blowing and synthetic jets for aerodynamic drag reduction of a simplified vehicle. Procedia Engineering 126, $388-392$.

3. Mohamed- Kassim, Z. Filippone, A. (2010). Fuel savings on a heavy vehicle via aerodynamic drag reduction. Transportation Research Part D 15, 275-284.

4. Ji-qiang, N. Dan, Z. Xi-feng, L. (2017). Experimental research on the aerodynamic characteristics of a high-speed train under different turbulence conditions. Experimental Thermal and Fluid Science 80,117-125.

5. Hassan S.M.R. Islam, T. Ali, M. Islam, Md. Q. (2014). Numerical Study on Aerodynamic Drag Reduction of Racing Cars. Procedia Engineering 90, 308 - 313.

6. Chilbule, C. Upadhyay, A. Mukkamala, Y. (2014). Profile modification of truck-trailer to prune the aerodynamic drag and its repercussion on fuel consumption. Procedia Engineering 97, 1208 - 1219.

7. Patil, C.N. Shashishekar, K.S. Balasubramanian, A.K. Subbaramaiah, S.V. (2012). Aerodynamic Study and drag coefficient optimization of passenger vehicle. International Journal of Engineering Research \& Technology (IJERT), 1(7), 1-8.

8. Chowdhury, H. Moria, H. Abdulkadir, A. Khan I. Alam, F. and Watkins, S. (2013). A Study on aerodynamic drag of a semi-trailer truck. Procedia Engineering, 56, 201-205.

9. Akansu, Y. E. Özmert, M. Frrat E. (2011). The effect of attack angle to vortex shedding phenomenon of flow around a square prism with a flow control rod. Journal of Thermal Science and Technology, 31, 1, 109120.

10. Bayındırlı, C., Çelik, M., Demiralp, M. (2018). The investigation of flow characteristic around a bus model by CFD method and improvement of drag force by passive flow control method. Journal Of Politeknik, Early appearance

format (DOI:10.2339/politeknik.403993)

11. Çengel, Y.A., and Cimbala, J.M. (2008). Akışkanlar Mekaniği Temelleri ve Uygulamaları, Güven Bilimsel Yayınları, 562599.

12. İnce, İ.T. (2010). Aerodynamic Analysis of GTD Model Administrative Service Vehicle PhD Thesis, Gazi Universty Institute of Science, Ankara, 30-66. 